\title{
Reflexões preliminares sobre as justificativas mítico- ideológicas para a hierarquização e a desigualdade social na era viking
}

\section{Preliminary reflections on the myth-ideological justifications for hierarchization and social inequality in the Vilking era}

\section{Reflexiones preliminares acerca de las justificaciones mítico- ideológicas de la jerarquización y la desigualdad social en la Era vilkinga}

\section{Patrick Zanon Guzzo}

patrickzanonguzzo@gmail.com

Universidade Federal Fluminense (UFF), Brasil

Recepção: 04 Abril 2020

Aprovação: 06 Julho 2020

Publicação: 01 Março 2021

Cita sugerida: Guzzo, P. Z. (2021). Reflexões preliminares sobre as justificativas mítico-ideológicas para a hierarquização e a desigualdade social na era viking. Sociedades Precapitalistas, 11, e061. https://doi.org/10.24215/22505121e061
Resumo: Este trabalho visa promover as discussões, bem como apresentar minhas primeiras reflexões sobre a relação da hierarquização e a desigualdade nas sociedades escandinavas da Era Viking. Para tanto, tomar-se-á como referência os versos que constituem o poema em chamado Rigspula (O conto de Rig), que integra a coletânea de texto da Edda Maior. Este poema apresentas a forma segundo a qual os mitos explicam o surgimento das camadas sociais entre os nórdicos, sendo, deste modo uma fonte central na discussão aqui sugerida.

Palavras-chave: Era Viking, Ideologia, Religião, Política.

Abstract: This work aims to promote the discussions as well as present my first reflections on the relationship of hierarchy and inequality in the Scandinavian societies of the Viking Age. To do so, we will take as reference the verses that constitute the poem in called Rigspula (The tale of Rig), that integrates the collection of text of Edda Major. This poem presents the way in which myths explain the emergence of the social strata among the Norse, being thus a central source in the discussion here suggested.

Keywords: Viking era, Ideology, Religion, Politics.

Resumen: El presente trabajo tuvo como objetivo estimular el debate, así como presentar mis primeras reflexiones acerca de la relación entre jerarquía y desigualdad en las sociedades escandinavas de la Era vikinga. Para eso, se toma como referencia los versos que componen el poema Rigspula (El cuento de Rig), que forma parte de la colección de textos de la Edda Mayor. Este poema presenta la manera en que los mitos explican el surgimiento de una jerarquía social entre los nórdicos, siendo así una documentación central en el debate que hicimos aquí.

Palabras clave: Era vikinga, Ideología, Religión, Política. 


\section{Introdução.}

A Religião ${ }^{1}$, em todas as suas múltiplas expressões, é geralmente entendida como um elemento meramente ideológico num sentido comum marxista, sendo ela vinculado ao que se considera ser a "superestrutura" das sociedades nos termos do materialismo histórico (Hobsbawm, 1998, p. 161). Assim, as, crenças e práticas religiosas seriam determinadas pelas relações dos homens com o meio, via trabalho, - a infraestrutura - dialeticamente, por seu turno, incorporaria elementos simbólicos advindos da superestrutura através de uma reação automática de causa e efeito. ${ }^{2}$ Porém, a resposta a esta impressão derivada da má compreensão, e consequente deformação das ideias dos idealizadores do materialismo histórico foram superadas por diversos pensadores marxistas que se ocuparam do tema como o filósofo Antonio Gramsci.

Reconsiderando as ideias e representações simbólicas que as classes sociais fazem de sua existência Gramsci propôs um modelo de entendimento da ideologia mais acurado do que o até então se estruturou sobre os textos então disponíveis de Marx e Engels. ${ }^{3} \mathrm{O}$ pensador italiano em suas reflexões sobre o assunto toma a Ideologia como um elemento estritamente necessário e constitutivo à existência das estruturas sociais haja vista, que ao se valer da ideia de "bloco histórico", afirma desta forma, o seguinte:

(...) as forças materiais são o conteúdo e as ideologias são a forma - sendo que esta distinção entre forma e conteúdo é puramente didática, já que as forças materiais não seriam historicamente concebíveis sem forma e as ideologias seriam fantasias sem forças materiais (Gramsci, 1984, p. 63).

A ideologia, portanto, a partir desta premissa deveria ser concebida sob duas formas: a primeira se referiria as ideologias historicamente orgânicas que, nas palavras do autor seriam "necessárias a uma determinada estrutura" (Gramsci, 1984, p. 62), uma vez que sua "validade" residiria no fato de que estas estruturas "psicológicas 'organizam' as massas humanas, formam o terreno sobre o qual os homens se movimentam e adquirem sua posição e lutam, etc.” (Gramsci, 1984, p. 62-63). E a segunda dá conta do que Gramsci entende serem as ideologias arbitrárias, que são "racionalistas" e "desejadas" (Gramsci, 1984, p. 62). Sobre elas o autor afirma o seguinte: "(...) elas [as ideologias arbitrárias] não criam senão movimentos individuais, polêmicas, etc." (Gramsci, 1984, p. 63). Seriam estas, portanto, discursos que funcionam como um contraponto da realidade histórica, que, ainda que elaboradas desta forma ideal teriam valor enquanto contraponto e, consequentemente, afirmação do real (Gramsci, 1984, p. 63).

As reflexões de Gramsci acima brevemente apresentadas a respeito do tema da ideologia são de grande valia para o entendimento do pensamento religioso nas sociedades pré-capitalistas. Tal como Ciro Cardoso, ao estudar o paganismo entre os anglo-saxões (Cardoso, 2004, p. 21), inclino-me a considerar que nas sociedades nórdicas da Era Viking a religiosidade se encaixaria como um dado a ser compreendido sob a luz do conceito gramaisciano de ideologia historicamente 
orgânica supracitado. Sendo assim, a religiosidade entre os nórdicos seria mais do que um mero exercício mental indolente para a tentativa da explicação, manutenção ou alteração da realidade social. Os mitos, ritos e práticas religiosas da Era Viking contém em si uma série de elementos que se configuram em acordo com a interação dos indivíduos com o meio e suas relações sociais, ou seja, em conformidade com as condições históricas em que eles estão inseridos. A este respeito Marx e Engels em Ideologia Alemã ${ }^{4}$ fazem as seguintes ponderações:

A produção de ideias, de representações, da consciência, está, em princípio, imediatamente entrelaçada com a atividade material e com o intercâmbio material dos homens, com a linguagem da vida real. O representar, o pensar, o intercâmbio espiritual dos homens ainda aparecem, aqui, como emanação direta de seu comportamento material. O mesmo vale para a produção espiritual, tal como ela se apresenta na linguagem da política, das leis, da moral, da religião, da metafísica etc. de um povo (Marx; Engels, 2007.p. 93-94).

Portanto, mais do que frutos decorrentes de epifanias, ou revelaçóes provenientes de entidades metafísicas de validade e valores atemporais, o discurso religioso é constituído entre os "vikings" como expressão de um discurso ideológico. Disso se pode pressupor que este conjunto de ideias tem como forja de sua constituição a realidade material na qual os homens desta sociedade interagem entre si e com o meio, sendo deste modo eminentemente histórico. Desta maneira deve se ter em vista que este conjunto de impressões da realidade, manifestado em práticas diversas - como rituais, celebrações, monumentos, etc. -, constitui uma fonte riquíssima e eloquente de informações a respeito dos mecanismos mentais que operavam e davam forma aos diversos elementos da sociedade de então.

\section{O Rigspula (o Conto de Rig) e a escravidão na Era Viking}

O que se pretende neste espaço, portanto, é demonstrar que no cerne do pensamento mítico das sociedades da Era Viking estabeleciam-se modos de compreensão de um universo fantasioso que em muito dialoga com as estruturas hierárquicas de então. Por meio da análise do surgimento dos cativos descrita no poema Rísspula (o Conto de Rig) pretende-se daqui em diante apresentar as correlações entre o que a fonte apresenta e as concepções e práticas sociais a respeito do tema por meio de fontes outras.

O poema Rígspula (o Conto de Rig), é parte integrante de um documento intitulado Codex Wormianus AM 242 folio) da Edda de Snorri Sturluson, datado aproximadamente de 1400 d.C. Ainda que pertencente a lista dos poemas da Edda Poética, as edições modernas desta obra em geral o incorporam ao restante dos textos da obra original dadas as suas características que fazem com que este seja encarado como sendo do mesmo estilo literário. A obra apresenta as justificativas segundo as quais os escravos ( Frall), os homens livres (Karl) e nobres ( $\mathrm{Jarl}$ ), são determinados enquanto tais pelo nascimento. Assim, obviamente, revela-se o caráter ideológico desta narrativa: a hegemonia do grupo dos homens nobres (Jarl) encontra razões de ser que se impóe não apenas por meios elaborados nas relações políticas do Midgard, mas por determinações divinas outorgadas pelos desígnios de Asgard. 
Frederic Armory, em um artigo (Armory, 2001, p. 17) sobre a relevância histórica do poema comenta que, apesar de interferências terem sido processos viáveis, e até mesmo naturais na redação do Rigspula, - em especial por conta da hegemonia do cristianismo nos tempos da transcrição da obra (Hill, 2002, p. 229-243) -, os vestígios históricos que remetem às características específicas da Era Viking podem ainda ser verificadas na obra. Segundo o autor, os aspectos sociais ali apresentados teriam muito mais a ver com os dos tempos dos vikings na Alta Idade Média do que quando redigida durante a coeva sociedade feudal escandinava do século XIII.

Sendo assim a intenção deste trabalho é vislumbrar pela Mitologia não um reflexo exato dos aspectos do pensamento dos homens na Era Viking. Ainda que fosse contemporânea ao tempo que descreve, esta obra jamais poderia ser entendida nestes termos. O poema Rigspula, a exemplo de toda e qualquer fonte histórica de caráter mítico, deve ser tomado como uma espécie de "casa de espelhos" diante da realidade à qual ela se destina: as imagens representadas nela são evidentemente distorcidas, e diante desta realidade não há escapatória. Porém ao serem evidenciadas em suas deformidades elas nos possibilitam entender os motivos para a sua produção segundo estes parâmetros.

Assim, não se furtando das dificuldades e polêmicas apresentadas sobre a fonte em questão procurar-se-á daqui em diante investir em uma perspectiva que entende o Rígspula pelas premissas supracitadas. Este poema pressupunha a ideia de que entre os indivíduos vigora a imposição de uma diferenciação social, tendência que se impunha entre os povos de origem germânica havia muito tempo, e que tiveram ao longo da Era Viking não só sua perpetuação, mas o seu aprofundamento.

Neste período estas diferenças irão também se demonstrar nas fontes por meio de critérios jurídicos. Apesar das dificuldades em se estabelecer quais efetivamente eram estes, é notório que a hierarquização da sociedade escandinava era um tipo de sociedade baseada em critérios desta natureza, como se pode verificar na no anel rúnico de Forsa, que é considerado pelos especialistas como o mais antigo registro deste tipo, tal qual aponta Stefan Brinks (Brinks, 2008, p. 28). A joia, cuja datação remete ao século IX, tem em sua extensão uma inscrição em que determina punições para aqueles que faltassem as assembleias. Porém o que mais chama atenção em relação ao tema da diferenciação social nesta fonte é a frase svað liudir aigu at liudrétti, cuja tradução dá a entender que as pessoas têm direitos conforme sua condição, de acordo com o que se determinou antes, segundo a lei da terra (Hälsinland) (Brinsks, 2008, p. 29). Esta proposição da interpretação do runologista norueguês Aslak Liestøl sobre o texto gravado no anel rúnico de Forsa tem respaldo na Heimskringla de Snorri Surtlusson, que tem uma leitura igualmente hierarquizada da sociedade (Bagge, 1999, p. 123-124). Segundo Aron I. Gurevitch, está associada às concepções legais dos povos germânicos na Idade Média a ideia de que os traços morais eram herdados, da mesma forma que os traços físicos. Assim, a beleza, a inteligência, a probidade e a magnitude seriam traços encontrados entre os chefes guerreiros, ao passo que traços vis seriam mais presentes entre os membros das camadas subalternas (Gurevitch, 1990, p. 191).

Os versos do Rígspula reforçam a ideia da associação das virtudes ou defeitos dos indivíduos com a sua condição social no nascimento. No poema, o deus 
Heimdall ao se disfarçar na forma de um homem chamado Rig - palavra cuja origem vem de "rei" em irlandês (Brinks, 2008, p. 50) ${ }^{6}$ - vai ao encontro de três casais. Em cada uma das visitas o deus divide a cama com cada casal por três noites e após nove meses as esposas engravidam de Heimdall/Rig, de modo que elas chamadas no poema de Bisavó, Avó e Mãe - concebem filhos que são nomeados, respectivamente, como Prell ("escravo"), Karl ("homem livre") e Jarl ("homem nobre") ${ }^{7}$.

Em razão da brevidade deste espaço me proponho a desenvolver em seguida uma breve reflexão sobre os determinantes ideológicos da condição de escravo no contexto da Era Viking. Ainda que a questão do peso relativo do seu contingente na sociedade mantenha-se como uma polêmica em aberto, é certo que eles existiram. As runestones ${ }^{8}$ de Hovgården (Brinks, 2008, p. 53) e Randbøl (Moltke, 1981, p. 296) - em que são encontradas inscrições que parecem se referir ao cargo de "mordomo", em geral exercido por cativos - e dados arqueológicos como os das "sepulturas duplas" encontradas na Noruega e na Suécia - nas quais os corpos dos escravos eram encontrados decapitados e de mãos atadas (o que denota sua condição de cativo) ao lado dos cadáveres de ricos ostentando seus bens - também demonstram que havia diferenças socioeconômicas entre os indivíduos (Brinks, 2008, p. 55). Portanto, a discussão aqui seria, no quadro destas diferenciações, qual o significado social da escravidão no contexto da Era Viking e em que sentido o Rígspula, ainda que distante da realidade que evoca, traz em si elementos desta significação.

Vejamos um trecho do poema de Heimdall/Rig posterior ao seu encontro com o casal designado por Bisavós. A passagem refere o descendente originado da relação com o deus, o filho Prall ("escravo"):

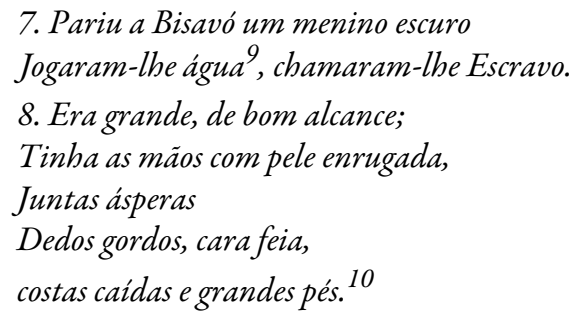

A definição feita pelo autor dos traços físicos em Frall tem por objetivo acentuar suas características abomináveis segundo os valores da sociedade da época. Percebe-se os esforços no mesmo sentido na estrofe em que Thir, futura esposa de Frell, surge na narrativa:

\section{0. À casa chegou uma moça com pernas tortas \\ Com os pés enlameados, braços curtidos \\ e nariz curvado, chamava-se escrava. ${ }^{11}$}

O significado do nome de seus descendentes do sexo masculino não foge à lógica até aqui apresentada, como se pode perceber ainda na transcrição a seguir:

12. Filhos tiveram, felizes estavam;

Creio que se chamavam Hreim e Fiósnir,

Klur e Kleggi, Kéfsit, Fúlnir,

Drumb, Digraldi, Drott e Hórvir, 


\section{Lut e Léggiald que faziam cercas, [de pedra] \\ Estercavam o campo, cuidavam dos porcos, \\ Guardavam as cabras, e extraiam a turfa. ${ }^{12}$}

Luis Lerate em uma nota de sua tradução da Edda Mayor - versão aqui utilizada - revela o significado de alguns dos nomes dos filhos de Frell e Thir, como é o caso do nome "Hreim", quem em espanhol seria "el gritón", expressão usada para definir indivíduos que falam num tom de voz muito alto. Já "Fiósnir", "el del establo", ou seja, o do estábulo; "Klut", "el patán", homem rústico, de hábitos grosseiros, expressão, inclusive, associada a trabalhadores do campo; "Fúlnir", "el protestón", indivíduo que reclama e/ou protesta por qualquer coisa; "Drumb", "el idiota", pessoa de pouca inteligência; Drott, "el vago", o preguiçoso e, por fim, Lut, "el encorvado", o encurvado. ${ }^{13}$

As filhas do casal também têm seus nomes associados a expressões pejorativas. Okkivinkalfa, por exemplo, seria a "la de gruesas panturrillas", ou seja, a de canelas grossas; Ámbat, "la sierva", a serva; Totrughypia, "la andrajosa", a maltrapilha; Tronubeina, "la de piernas de grulla", a de pernas de grua. ${ }^{14}$ Aqui há provavelmente uma referência às fêmeas da espécie Grou-comum (Grus grus). Estas aves acinzentadas e de longas patas traseiras migram para a Escandinávia na chegada da primavera, época em que se reproduzem e fazem seus ninhos nos pântanos, como afirma o ornitólogo Paul Johnsgard (Johnsgard, 1983).

Como se pode notar, o texto estabelece uma visão estereotipada dos escravos. Inclusive, por esta razão Stefan Brink entende que o Rígspula deve ser usado com muito cuidado como fonte histórica para se entender esta categoria social (Brinks, 2008, p. 49-56). Concordo plenamente com esta ponderação do autor, porém, a meu ver, é assinalável a intenção do poeta de estabelecer, através da metafórica origem dos escravos não apenas uma diferenciação pela inferiorização, mas também uma subordinação evidente dos escravos aos "homens livres". O próprio Brink vai apostar neste aspecto ao definir os termos segundo os quais a liberdade era entendida na época:

Liberdade não era definida como liberdade individual, mas sim como o direito de pertencer a um coletivo (fellowship), ser parte de um grupo social. Um estranho era frequentemente considerado como inimigo. É nessa perspectiva que temos que entender como nossos antepassados podem aceitar e até mesmo justificar a escravidão (Brinks, p. 50).

O escravo entre outras coisas era, portanto, um indivíduo que não pertencia plenamente à comunidade. E ainda, como Frederic Armory alerta, o fato de o escravo ter nascido do casal de bisavós, - antes, portanto, dos Karl e dos Jarl-isto significaria que eles eram mesmo antes do surgimento de seus mestres servindo pois de exemplos para os demais cativos que surgiriam. Tais quais Frell eles seriam repulsivos desde a sua criação. Sendo assim o escravo na Era Viking não gozava de direitos como os demais membros da sociedade por estar submetido a uma relação de dependência pessoal (Armory, 2001, p.7). E essa se configura por tantas razões quanto se pode verificar na polissemia dos termos que usados para caracterizálos como cativos (Karras, 1988, p. 46-50). Desde o ofício de concubinagem ao trabalho nos campos, esta mão-de-obra se fez presente entre os vikings. E ainda que poucos tenham sido seus registros dentro da Escandinávia, é notório que a escravidão tenha sido grande filão comercial para os nórdicos além de suas terras, 
tal como comprova a arqueologia (Karras, 1988, p. 41-46). Os escravos por eles comerciados eram mercadoria valiosa na época, e por vezes sua posse era um signo de poder entre os grandes proprietários.

\section{O Rígspula, o Requerimiento e a questão do "Outro"}

Por todas as razões elencadas até aqui, tendo a crer que era desejável aos mandatários das sociedades nórdicas do alto-medievo que os escravos fossem compreendidos como elementos estranhos à comunidade. E à religião, neste sentido, coube o papel de expressar esta diferenciação de modo a demonstrar as razões pelas quais os escravos não só eram "outros", mas subalternos. Assim, acredito que as reflexões de Tzvetan Todorov sobre o papel da alteridade na conquista da América sejam de grande valia para pensar o Rígspula. O discurso do poema apresenta uma contradição que em diversos pontos se assemelha às verificadas por Todorov ao analisar o célebre documento intitulado Requerimiento ou injunção dirigida aos índios. Lembro que o mesmo procurava legalizar a dominação, pelos colonizadores espanhóis, das populações ameríndias, promovendo uma argumentação de viés religioso. Logo em sua introdução, o Requerimiento apresenta resumidamente a história da humanidade que teria, por ponto culminante, a encarnação de Cristo, considerado "chefe da linhagem humana” e cuja hegemonia se estendia por todo o universo. Por conseguinte, Jesus teria transmitido sua autoridade a Pedro, o primeiro papa, e esse aos seus sucessores. Entre os pontífices, um deles havia entregue o continente americano aos espanhóis e aos portugueses, de modo que caberia aos colonizadores informar este desígnio aos indígenas.

Assim, a leitura do Requerimiento era feita na presença de um oficial do rei, de modo a informar às populações autóctones - ainda que não necessariamente por meio de um intérprete - sobre a doação do continente americano aos colonizadores ibéricos. Daí se impunha aos indígenas, inevitavelmente, a dominação sob duas formas: ou aceitavam a hegemonia dos europeus e eram assimilados pela lógica social imposta pelos colonizadores ou, em caso de resistência, seriam submetidos à escravidão.

A respeito dos pormenores da justificativa religiosa desta situação, Todorov argumenta que o Cristianismo aqui manifesto é atravessado por uma enorme contradição, pois, embora se defina como uma religião igualitária assume-se, neste caso, como razão para a escravidão. Segundo Todorov:

\footnotetext{
Não somente poder espiritual e poder temporal se encontram confundidos, o que é tendência de toda e qualquer ideologia de Estado - que decorra, ou não do Evangelho - como, além do mais os índios só podiam escolher entre duas opções de inferioridade: ou se submetem de livre e espontânea vontade, ou serão submetidos à força e escravizados. (....) A superioridade dos que enunciam o Requerimiento, podese dizer, já está contida no fato de serem eles os que falam enquanto os índios escutam (Todorov, 1982, p. 145).
}

Trata-se, obviamente, de dois contextos distintos, porém consigo enxergar paralelos interessantes não nos fatos em si, mas na base da construção ideológica que estrutura o Requerimiento e o Rigspula. Assim como os índios na América sob o domínio espanhol, os escravos submetidos na sociedade dos vikings tinham sua condição ideologicamente imposta pela ação e determinação de um deus 
que os circunscreve à condição de subalternos. Talvez por isso, mesmo quando os cativos conseguiam a sua manumissão eram, em algumas regióes, por pelo menos quatro gerações, ainda "maculados" pelo seu status inferior. E, apesar de lhes serem dirigidas algumas concessões, como o acúmulo de economias para a compra da liberdade, não lhes era dado o direito de receber nenhum tipo de herança, nem de legá-la a alguém, bem como de participar de qualquer tipo de transação (Langer, 2017, 646). Enfim, ao escravo na Era Viking restava, segundo pretendiam os registros considerados, sujeitar-se às determinações do seu senhor, que poderia dispor plenamente de sua vida. E a justificativa da natureza de tal relação não se revestia apenas de critérios mundanos, mas era essencialmente sancionada pelas próprias divindades.

Deste modo, cabe considerar que as sociedades nórdicas, ainda que marcadas por uma mobilidade de influência política, baseada em relações entre os indivíduos e suas relações de dependência, como demonstra Wickham (Wickham, 2015, p. 141-157), e senso comunitário manifesto até mesmo em sua organização política, como era o caso das Things, os status sociais eram muito bem demarcados entre os vikings (Karras, 1988, p. 40), sendo pois a escravidão, aqui analisada, um exemplo salutar de como esta se desdobrava dentro de uma perspectiva mítica desta sociedade. As classes sociais aqui se expressam, tal como colocado, não apenas nas tensões da vida mundana, mas se manifestam também em sua forma de concepção segundo o Rígspula, de modo que não seria apenas uma diferenciação econômica, social, ou jurídica, mas, uma imposição celestial.

\section{Documentos:}

Andrade, Maria Cecília Albernaz Lins Silva de. A Germania de Tácito: tradução e comentários. São Paulo. 2011, 118 f. Dissertação (Mestrado em Letras) -Programa de Pós-Graduação em Letras Clássicas do Departamento de Letras Clássicas e Vernáculas da Faculdade de Filosofia, Letras e Ciências Humanas da Universidade de São Paulo, Universidade de São Paulo, São Paulo, 2011.

EL CUENTO DE RIG (Rígspula) In: EDDA MAYOR. Luis Lerate (trad.). Madrid: Alianza. 1986. (p. 147-154).

\section{Referências}

Armory, F. (2001). The Historical Worth of Rígspula. Alvissmál, 10, 3-20.

Bagge, S. (1991). Society and Politics in Snorri Sturluson's Heimskringla. Berkeley: University of California Press. Disponível em: http://ark.cdlib.org/ark:/13030/ ft0f59n6wc/. Acessado em 05. jun. 2020

Brink, S. (2008). Slavery in the Viking Age. In S. Brink (Ed.), The Viking world (p. 49-56). London: Routledge.

Brinks, S. (2008). Law and Society. In S. Brink (Ed.), The Viking World (p. 23-31). London. Routledge.

Cardoso, C. F. S. (2004). O paganismo anglo-saxão: uma síntese crítica. Brathair, 4(1), 21. Disponível em http://ppg.revistas.uema.br/index.php/brathair/article/view File/625/548. Acessado em 29. dez. 2016

Costa Neto, P. L. (2010). Notas introdutórias sobre a publicação das obras de Marx e Engels. Crítica Marxista (São Paulo), 30, 49-65. Disponível 
em: https://www.ifch.unicamp.br/criticamarxista/arquivos_biblioteca/artigo17 9artigo5.pdf. Acessado em 06. ago. 2018.

Gramsci, A. (1984). A Concep̧̧ão dialética da história. Rio de Janeiro: Civilização Brasileira.

Gurevitch, A. I. (1990). As categorias da Cultura Medieval. Lisboa: Caminho.

Hill, T. D. (1980). Rígspula: some medieval Christian analogues. In P. Acker \& E. Hobsbawm, História do marxismo 1 - O marxismo no tempo de Marx. Rio de Janeiro: Paz e Terra.

Hobsbawm, E. J. (1998). Sobre História. São Paulo: Companhia das Letras.

Johnsgard, P. A. (2017). Cranes of the World: Eurasian Crane (Grus grus). In P. Johnsgard, Cranes (p. 227-237). University of Nebraska - Lincoln DigitalCommons@University of Nebraska - Lincoln. Disponível em: http://di gitalcommons.unl.edu/bioscicranes/. Acessado em 20. nov. 2017.

Karras, R. M. (1988). Slavery and Society in Medieval Scandinavia. New Haven: Yale University Press.

Langer, J. (2017). Dicionário de História e Cultura da Era Viking. São Paulo: Hedra.

Larrington, C. (eds.) (2002). The Poetic Edda: essays on Old Norse Mythologie (p. 229243). Londres: Routledge.

Marx, K. y Engels, F. (2011). O 18 brumário de Luis Bonaparte. São Paulo: Boitempo.

Marx, K. y Engels, F. (2007). A Ideologia Alemã. São Paulo: Boitempo.

Moltke, E. (1981). Runes and their origin. Denmark and elsewhere. Peter Foote: Copenhagen.

Todorov, T. (1982). A conquista da América: a questão do outro. São Paulo, SP: Martins Fontes.

Wickham, C. (2015). Passage to Feudalism in Medieval Scandinavian. In L. Graca y A. Zingarelli (Eds.), Studies on Pre-Capitalist Mode of Production (p. 141-157). Leiden, Boston: BRILL. Historical materialism book series, Vol. 97, Disponível em: https://brill.com/view/book/edcoll/9789004263703/B9789004263703_0 06.xml. Acessado em 26. jul. 2018.

\section{Notas}

1 Resenha biográfica: $O$ autor é doutorando em História pelo Programa de Pós Graduação em História da Universidade Federal Fluminense (PPGH-UFF); Atualmente é bolsista de doutorado do Conselho Nacional de Desenvolvimento Científico e Tecnológico. Também é membro do grupo de estudos Translatio Studii da Universidade Federal Fluminense e membro do Niep-Prék, Grupo de Trabalho sobre sociedades pré-capitalistas do Núcleo Interdisciplinar de Estudos e Pesquisas em Marx e Marxismo, da Universidade Federal Fluminense

2 A respeito da questão da determinação dialética que se estabelece entre infraestrutura e superestrutura Mannheim, por exemplo, esclarece qual seria a real medida desta, em termos históricos e científicos, como se pode notar na definição a seguir: "Por "determinação" não nos referimos (...) a uma sequência mecânica de causa-efeito: deixamos em aberto o significado de "determinação", e somente a investigação empírica nos poderá mostrar até que ponto é estrita a correlação entre situação de vida e processo de pensamento, ou qual a gama de variações existente na correlação In: MANNHEIM K. Ideologia e Utopia. Tradução de Sérgio M. Santeiro. Rio de Janeiro, Editora Guanabara, 1986, p. 289.

3 Cabe aqui considerar que os entraves editoriais que envolvem a produção e divulgação de Marx e Engels foram responsáveis, direta ou indiretamente por uma série de dificuldades da compreensão geral de sua obra. Estes foram publicados pela primeira 
vez muito depois da morte de seus autores, como é o caso de A Ideologia Alemã, que só pode ser acessível ao grande público (fluente em alemão) graças à Bernstein em 1902-1903, que o publicou na sua revista de teoria e de bibliografia socialistas, Dokumente des Sozialismus. (Costa Neto, P. L. 2018). No mais as obras de Marx e Engels representaram para muitos um perigo, dado o teor revolucionário de seu conteúdo. Até mesmo entre os que, em tese, interessaria a difusão das ideias dos dois autorees havia discordâncias em torno da elaboração de edições de suas obras, tal como demonstra Hobsbawn ao comentar a postura do Partido Social-Democrata alemã sobre o tema: "O Partido Social-Democrata Alemão, que possuía o Nachlass dos fundadores, não fez nenhuma tentativa de publicar suas obras completas; e é mesmo possível que julgasse contraproducente a publicação ou a reedição de algumas de suas observações mais virulentas e ofensivas, ou de escritos políticos que conservavam um interesse puramente contingente." (Hobsbaem, 1980. p. 428-429). Tais problemas obviamente impediram os pensadores posteriores de terem uma visão clara do que seria o conceito de Ideologia para Marx e Engels, o que fez com que tal ferramenta teórica não pudesse ser usada e aprimorada por estes pensadores conforme sua concepção original.

4 Cabe dizer aqui que, embora seja recorrente na vulgata marxista o entendimento deste trecho sob a luz da dicotomia estrutura-superestrutura aqui veemente criticada, o dos pensamentos dos autores passa ao largo desta interpretação superficial. Marx e Engels embora enfatizassem as distinções econômicas entre os indivíduos também refletem a respeito da concepção das classes sociais se constituírem para além de suas funções dentro da mecânica das forcas produtivas. Um exemplo interessante neste sentido pode se verificar em obras como "O 18 de Brumário de Luís Bonaparte”, onde Marx demonstra o quão dinâmicas e complexas são as relações de classe e intraclassistas, tal quando descreve a guinada a trajetória da burguesia desde os tempos medievais de classe subalterna até, enfim, se tornar classe dominante em 1818. (Marx, K. y Engels, F., 2011).

5 EL CUENTO DE RIG (Rígspula) In: EDDA MAYOR. Luis Lerate (trad.). Madrid: Alianza. 1986. p. 147-154.

$6 R i g$, vem do nome Rigr, que é uma palavra do idioma irlandês Ir rí, OIr ríg, que significa 'rei'. Cf. BRINK, Stefan. Slavery in the Viking Age. In: Brink, Stefan (Ed.). The Viking world. London: Routledge, 2008. p. 49-56. p. 50.

7 EL CUENTO DE RIG (Rigspula) In: EDDA MAYOR. Op. Cit. p. 147-154.

8 As Runestones monólitos encontrados ao longo da Escandinávia nos quais se podem verificar a escrita de runas. Eram geralmente erguidos em homenagem às pessoas de grande poder, riqueza e influência. $\mathrm{O}$ fato de apenas duas destas pedras aqui abordadas mencionarem escravos não apenas demonstra sua existência nas sociedades nórdicas alto medievais, mas também o quão raramente eram prestigiados por seus senhores.

9 Uma nota explicativa na versão da Edda traduzida por Luiz Lerate diz que este ato remete ao batismo pagão. Cf. EDDA MAYOR. Luis Lerate (trad.). Madrid: Alianza. 1986. p. 148.

10 EL CUENTO DE RIG (Rigspula) In: EDDA MAYOR. Op. Cit. p. 148.

11 EL CUENTO DE RIG (Rígspula) In: EDDA MAYOR. Idem. p. 148.

12 EL CUENTO DE RIG (Rigspula) In: EDDA MAYOR. Idem. p. 148-149.

13 Nota 7. Cf. EDDA MAYOR. Luis Lerate (trad.). Madrid: Alianza. 1986. P. 149.

14 Nota 8. Cf. EDDA MAYOR. Luis Lerate (trad.). Madrid: Alianza. 1986. P. 149. 